\title{
Polifonías de los cuerpos de los bebés desde el pensamiento docente: lecturas de desarrollo que hacen las maestras
}

Volumen 6 N. ${ }^{\circ} 48$ enero-junio de 2020

ISSN: 0122-4328

ISSN-E: 2619-6069

pp. 104-115
Polyphonies of the Bodies of Babies from Teacher Thoughts: Developmental Readings by Teachers
Polifonias dos corpos de bebês a partir do pensamento do professor: leituras do desenvolvimento feitas por professoras

Mónica Gil Cardona*

Fecha de recepción: 01-03-20

Fecha de aprobación: 07-04-20

\section{PARA CITAR ESTE ARTÍCULO}

Gil Cardona, M. (2020). Polifonias de los cuerpos de los bebés desde el pensamiento docente: lecturas de desarrollo que hacen las maestras. Nodos y Nudos, 6(48). https://doi.org/ 10.17227/nyn.vol6.num48-11390 


\section{RESUMEN}

Este artículo constituye la reflexión a partir de la investigación de corte cualitativo sobre las creencias acerca de cuerpo y movimiento de dos maestras de Educación Inicial, desde la pregunta: ¿Cómo se comprende el desarrollo de los bebés, desde las creencias de cuerpo y movimiento que tienen las dos maestras de sala materna del Jardin Infantil La Florida? En

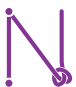

Volumen 6 N. ${ }^{\circ} 48$ enero-junio de 2020 ISSN: 0122-4328 ISSN-E: 2619-6069 pp. $104-115$ cuanto a la metodología, se asume la realidad desde un enfoque interpretativo proveniente de la fenomenología social y la sociología del conocimiento, por esta vía la estrategia que se utiliza para acercarse a la realidad es el Estudio de Caso, usando dos instrumentos para recolectar la información: la observación video grabada y la entrevista semiestructurada. En cuanto a la técnica de análisis de información, se utilizó el análisis de contenido, a partir de ello el estudio mostró que las observaciones sobre cuerpo y movimiento que hacen las maestras se relacionan con sus creencias sobre el desarrollo e inciden en sus propuestas.

Palabras clave: pensamiento del profesor; creencias; cuerpo; movimiento; desarrollo

\section{ABSTRACT}

This article constitutes the reflection based on the qualitative research on the beliefs about body and movement of two Early Childhood Education teachers, from the question: How is the development of babies understood, from the beliefs of the body and movement that the two teachers of the nursery school of the La Florida Kindergarten have? Regarding the methodology, reality is assumed from an interpretive approach from the social phenomenology and the sociology of knowledge. In this way, the strategy used to get closer to reality is the case study, using two instruments to collect the information: the recorded video observation and the semi-structured interview. Regarding the information analysis technique, content analysis was used, from which the study showed that the observations on body and movement made by the teachers are related to their beliefs about development and these affect their proposals.

Keywords: teacher thinking; beliefs; body; movement; development

\section{RESUMO}

Este artigo constitui a reflexão a partir da pesquisa qualitativa sobre as crenças sobre corpo e movimento de duas professoras de Educação Infantil, a partir do questionamento: Como se compreende o desenvolvimento dos bebês, a partir das crenças do corpo e o movimento que têm as duas professoras da creche do Jardim de Infância La Florida? No que se refere à metodologia, a realidade é assumida a partir de uma abordagem interpretativa a partir da fenomenologia social e da sociologia do conhecimento, desta forma a estratégia usada para se aproximar da realidade é o estudo de caso, utilizando dois instrumentos de coleta de informações: a observação em vídeo gravado e a entrevista semiestruturada. Quanto à técnica de análise de informações, utilizou-se a análise de conteúdo, a partir da qual o estudo evidenciou que as observações sobre corpo e movimento feitas pelos professores estão relacionadas às suas crenças sobre o desenvolvimento e estas afetam suas propostas.

Palavras-chave: pensamento do professor; crenças; corpo; movimento; desenvolvimento 


\section{Introducción: el aula como espacio polifónico}

La investigación ${ }^{1}$ tiene lugar a partir del año 2016 cuando tenía un vínculo laboral con el Jardín Infantil La Florida² (J. I. La Florida), desde entonces el interés por el cuerpo y el movimiento se habian hecho presente en las acciones que siendo maestra pude vivenciar con los niños, pues en el aula tenían lugar las experiencias de planear, llevar a cabo y reflexionar sobre las relaciones que se establecen con y desde los niños y niñas con quienes se habita ese espacio, y desde alli se empieza a comprender el lugar comunicativo que tienen esas corporeidades, así como los significados que se pueden develar al adentrarse en las creencias de las maestras sobre cuerpo, movimiento y desarrollo del grupo de niñas y niños que tiene a su cargo. Desde el pensamiento de las docentes se abre la oportunidad de comprender los sentidos y significados que llevan a la toma de decisiones y a las reflexiones que guían su acción.

A través de las observaciones y acompañamiento a las relaciones entre maestras y niños y niñas se comprende la relevancia que otorgan al cuerpo y el movimiento, y privilegian la observación pues desde alli pueden comprender lo que sucede con cada uno de sus niños y niñas en cuanto a desarrollo. Por esta vía la investigación se va situando en un interés que no es nuevo, la línea vivencial de la práctica psicomotriz educativa (Aucouturier, 2004; Lapierre, 1982; Llorca et ál., 2002).

Esta línea se convierte en la condición de posibilidad para comprender la escuela como un espacio relacional y vivenciado que provoca "el desarrollo emocional, el desarrollo evolutivo global, la socialización y la consecución de la mayor autonomía posible" (Llorca et ál., 2002, p. 103). Todo ello desde la relación con los otros, pues su principio fundamental es básicamente permitirle a la niña y al niño desplegar todas sus

1 La investigación se realiza en el marco de la Maestría en Estudios en Infancia desarrollada entre los años 2016 y 2017.

2 El Jardín Infantil La Florida hace parte de las instituciones cofinanciadas por la Secretaría Distrital de Integración social de la localidad de Engativá.

3 En esta investigación se utiliza la palabra aula para referirse a ese espacio donde se construye constantemente un saber pedagógico, escenario privilegiado de prácticas donde se reconoce la participación activa tanto de maestros como de niñas, niños y sus familias. potencialidades simbólicas para conseguir los placeres del saber y de la cultura, con la ayuda del profesional que comprenda el valor del cuerpo y del movimiento como ejes fundamentales del desarrollo psíquico, afectivo y social del ser humano (Aucouturier, 2004).

La práctica psicomotriz sensibiliza al maestro o maestra sugiriendo no solo observar sino relacionarse con los niños y niñas a través del juego y el contacto, asunto que redunda en un valor otorgado a las distintas maneras de relación que tiene cada uno. Al transitar por este camino se van encontrando los significados de acción motriz individual y colectiva, la relación de maestras y niños o niñas con el tiempo, los objetos y los otros que en conjunto serán parte fundamental de su desarrollo. por ello, cada paso investigativo estaba acompañado de un esfuerzo por comprender el tejido relacional de esos espacios pedagógicos para acercarse a las creencias de las maestras. Tal sensibilidad frente a lo que sucede con el cuerpo y el movimiento posibilita la escucha de la polifonía del aula en clave de creencia.

\section{Del horizonte metodológico}

Dicho camino lleva a comprender que la pregunta de investigación "¿Cómo se comprende el desarrollo de los bebés, desde las creencias de cuerpo y movimiento que tienen las dos maestras de sala materna del Jardín Infantil La Florida?" asume la realidad social desde un enfoque interpretativo proveniente de la fenomenología social y la sociología del conocimiento (Carr y Kemmis, 1988), dado que aquello que sucede en el J. I. La Florida proviene de unas estructuras significativas construidas por los miembros individuales de dicha realidad, en este caso las maestras, las niñas y los niños.

Por lo anterior, el diseño metodológico acoge un enfoque que permite la interpretación de esa realidad transformada constantemente por quienes sientan las bases de los significados compartidos en sus interacciones.

Era necesario, entonces, encontrar instrumentos de investigación que permitieran acercarse al inventario de esa realidad accediendo a los significados que pasan desapercibidos en la cotidianidad. Se elige así, por un lado, la observación de la práctica y se 
solicita a las maestras grabar una sesión que previamente planearan y realizaran con su grupo para, desde allí, plantear la entrevista semiestructurada que se utilizaría como instrumento para adentrarse en los sentidos y significados condensados en la cotidianidad de las aulas. Por otro, la categorización inductiva y la codificación (Bonilla y Rodríguez, 1997) se eligen como técnicas propias del análisis de contenido.

Las decisiones para centrar la investigación en un grupo particular y adentrarse en sus significados adquieren relevancia, y la estrategia del estudio de caso es la que mejor define las intenciones de comprender esta realidad social que tiene un lugar importante en el diario vivir de quien emprende la investigación. El estudio de caso abriría las puertas a la comprensión de esa dimensión subjetiva de la realidad como lo dicen Bonilla y Rodríguez (1997), pues esto solo es posible estudiando a profundidad un caso para encontrar las propiedades esenciales de aquello que se está considerando.

\section{Cuerpo, movimiento y desarrollo}

La línea vivencial de la práctica psicomotriz se constituye en el marco conceptual desde donde se entienden estas categorías. El cuerpo se comprende como unidad, como un todo no fragmentado, por esta vía del psicoanálisis y la psicomotricidad relacional (Aucouturier, 2004) se entiende que este asunto de sentirse unificado es provisto por una especie de envoltura construida por medio del contacto, el movimiento y los olores, en fin una serie de sensaciones que permiten sentirse contenido. Ya desde el nacimiento esa sensación de tener un cuerpo disperso va evolucionando hasta llegar a sentirse unidad, más aún sentirse entero y seguro, asunto indispensable en el desarrollo global de niñas y niños que involucra cuerpo y psiquis en un proceso que se vive en doble vía, pues el acto motor se vivencia tanto externa como internamente, y va desplegando niveles funcionales cada vez más complejos, lo cual demanda del cuerpo una relación de su conjunto tanto fisiológico como psíquico y afectivo.

Esta experiencia configura la identidad de cada niña o niño y depende principalmente de las oportunidades que tienen de vivir transformaciones mutuas con su entorno, pues alli es donde se sienten cuerpo presente. Aucouturier (2004) dice al respecto: "hay una relación intensa entre el niño y su espacio, vivido como espacio vital, indispensable para la existencia por lo que ha de ser defendido constantemente" (p. 123). Entonces ese espacio no es solo un área física que se ocupa, es un territorio en el cual se debe tener la oportunidad de transformar, de participar e incidir permanentemente, ya que desde allí se construye dicha conciencia de cuerpo como unidad, es un espacio con significado importante para la vida y desarrollo.

Este camino resulta interesante en un contexto educativo, pues ese espacio al que llamamos pedagógico debe proveer oportunidades de transformación para niños y niñas, con adultos sensibles al lenguaje psicomotor. El maestro o maestra se transforma en observador de la expresividad motriz, hace parte de esas relaciones mediadas por el cuerpo, atento a las interacciones de esos primeros años de vida porque conoce lo determinante que resulta para la construcción de la identidad, para ampliar esa capacidad de asombro, ese interés por descubrir, comunicarse o aprender, pues su saber le advierte de la complejidad que llegan a alcanzar y lo dinámicos que llegan a ser.

El movimiento reviste de gran valor los cuerpos de los niños y niñas, pues constituye la oportunidad de existir visible desde la posibilidad de comunicar, descubrir y transformar los espacios que habita. Además, le devela a la maestra los lenguajes infantiles a los cuales necesita acceder para comprender el desarrollo individual y colectivo, los pasos que la niña o el niño está recorriendo hacia la madurez, y el conocimiento indispensable para fortalecer su trabajo pedagógico.

Un aspecto fundamental en el asunto relacionado con el acto motor es el movimiento y el desarrollo, expuesto por Wallon mucho antes que Aucouturier, es lo concerniente a su relación con lo emocional y lo afectivo, donde se privilegian las transformaciones mutuas que puedan suceder en la relación con el entorno, dentro de todo un proceso de desarrollo del pensamiento que tiene incidencia en la vida orgánica y psíquica de la niña o niño y termina siendo la fuente de la acción motriz y de la comunicación. Así las cosas, el desarrollo se entiende como un asunto en el que cuerpo y psiquismo se unen para transformar 
el entorno, asumiendo el afecto y la relación como asuntos fundamentales. Lo afectivo muchas veces se sitúa en segundo plano dentro de la educación, porque se piensa, por un lado, que la emoción y el afecto no se relacionan con el desarrollo del pensamiento $y_{\text {, }}$ por otro lado, se ubica como expresión maternal que puede desdibujar la acción pedagógica que realiza un maestro o maestra.

Wallon (1984) entiende que el cuerpo y el movimiento, en relación con la vida psicológica del niño, transitan en diferentes direcciones sin abandonar lo sucesivo, que desde luego es evidente dado que el niño muestra sus ajustes posturales y su evolución mental en acciones que van de lo pulsional a lo simbólico. El autor propone ver las etapas de desarrollo como momentos en los cuales el niño vive un proceso interno y externo complejo que requiere de su comprensión en lo concerniente a lo corporal, lo afectivo, lo cognitivo y lo psíquico en función de aquello que le propone el medio. "Los progresos del niño no son una simple adición de funciones. El comportamiento de cada edad es un sistema en el que cada una de las actividades ya posibles concurre con todas las otras, recibiendo su papel de conjunto" (p. 26).

De manera tal que, si el desarrollo funciona como un conjunto se tiene que pensar en la relación del todo con sus partes, dado que esta es la base del concepto propiamente dicho. Al ser conjunto el desarrollo no periodiza porque se construye gracias a la relación entre sus partes, ya que ellas van determinando la forma del todo, al que llamamos desarrollo. Se reconoce entonces su valor por la relación entre sus partes, su dinámica propia y poder creativo, otorgándole además su característica global, por ello se entiende el desarrollo como un proceso sucesivo y simultáneo.

El encuentro con los niños y las niñas desde este marco de ideas es un encuentro con la fuerza creadora de identidades, un encuentro con un lenguaje poderoso que muchas veces no halla lugar para el diálogo porque se privilegian intenciones utilitaristas, mecanicistas y dominantes, desde donde el maestro o maestra direcciona las acciones, coarta la expresividad y reduce la comunicación a una sola voz: la propia.

Para terminar este apartado sobre las grandes categorías abordadas en la investigación, es necesario hablar del pensamiento del profesor, aceptado por la comunidad científica desde 1975. Desde aqui la investigación enfocará su preocupación por conocer cuáles son los procesos de pensamiento alrededor del cuerpo, el movimiento y el desarrollo.

Esta postura entiende que la actividad del maestro va más allá de la mera transmisión de conocimientos, y que es un:

profesional activo, inteligente, cuya actividad incluye: establecimiento de objetivos; búsqueda de información acerca de los alumnos y el currículo en el contexto de los objetivos; formulación de hipótesis sobre la base de esta información; su propia disposición de la enseñanza y el ambiente; y seleccionar entre diversos métodos de enseñanza. (Shavelson y Borko, citados por Marcelo, 1987, p. 16)

Por ello, sus decisiones en medio de las situaciones vivenciadas en el aula definen en gran medida las características de su experiencia.

\section{Resultados}

Para acercarse a los resultados de esta investigación es necesario entender su relación con el propósito de ella, el cual, como ya se indicó, tiene que ver con indagar, comprender y reflexionar acerca de las creencias de las maestras sobre cuerpo, movimiento y desarrollo, y la relación que se establece entre estas creencias. Por tanto, a continuación, se presentarán las categorias que emergieron del análisis de la información:

\section{Creencia sobre cuerpo: el cuerpo posee un lenguaje desde el cual se comprende el desarrollo}

Las maestras comprenden ese poder comunicativo que posee el cuerpo al empezar mencionando sus propias vivencias para afirmarlo, reconocen cómo el cuerpo hace uso de los mediadores de la comunicación -gestos, miradas, tacto, tono de voz y silencios serán mediadores de comunicación (Lapierre, 1982)y cómo estos les permiten exponerse, contar no solo lo que suscita en ellas la situación actual, sino además reflejar su propia historia afectiva.

leen nuestro lenguaje corporal, reciben toda esa información que nosotros estamos transmitiendo con 
nuestros modales, con nuestros gestos, nuestras miradas, la forma de movernos. (M.1, p. 38)

El cuerpo comunica, y las maestras participan de esa comunicación implicándose corporalmente con su grupo porque entienden que solo a través del cuerpo llegan a entender a las niñas y niños, y a construir relaciones que les permitirá proponer situaciones de aprendizaje, así como comprender, acompañar y jalonar los procesos de desarrollo.

\section{Creencias sobre movimiento: el movimiento es la posibilidad de existencia y desarrollo. Vínculo, placer, libertad e imitación}

La construcción del vínculo afectivo ofrece confianza y seguridad: la confianza que ofrece el vínculo construido permite a los niños y niñas moverse a ritmo propio, descubrir y conquistar las posibilidades motrices de su cuerpo y a través de ellas aventurarse a tocar el mundo de los objetos. El afecto, por su parte, les permite estar seguros, condición para el aprendizaje que en este sentido transita por la vía del contacto o, mejor, por la vía de la comunicación corporal; leámoslo en sus palabras:

\section{El niño se va a sentir con confianza de seguir explorando porque el niño ya logró esa primera etapa de poder subir hasta ese punto y alcanzar su objeto. (M.1, p. 56)}

Esa confianza ofrendada por el vínculo afectivo provee la posibilidad de movimiento; no solo un espacio amplio o unos objetos potentes en términos de exploración provocan el movimiento, la maestra nos dice a continuación que la seguridad y la confianza se construyen a través del movimiento, de la disposición al contacto, es decir, de una actitud empática (Aucouturier, 2004) depende el movimiento, conquistar su cuerpo y explorar el espacio que les rodea. Entonces, ese "dar la mano o estar pendiente" es entablar un diálogo tónico emocional, que permita la comunicación y la confianza de vencer los miedos y explorar otras posibilidades motrices.

la confianza, todo debe estar enfocado a la seguridad, porque al ser tan pequeños lo necesitan, si no tienen seguridad no van hacer nada se quedan quietos, al principio del año habian niños que no caminaban, entonces se quedaban ahi quietos porque... si no saben, pues hay que darles la confianza porque no tenían la seguridad de su cuerpo, hay que hacer experiencias donde la seguridad de su cuerpo haga que se sientan seguros, nosotros lo logramos estando pendientes, si uno no les estira la mano pues no lo hacian. Estar ahi, estar pendiente, el contacto que la docente le brinda al niño para poder seguir, para que avance. (M.2, p. 71)

Construir el vínculo, por tanto, merece la planeación y el diseño de "experiencias que hagan que se sienta seguro", pues si se siente seguro podrá moverse y conquistar el espacio en otro plano, el vertical. Esta experiencia es trascendental en la vida del niño o niña, tanto que se vive como un segundo nacimiento (Aucouturier, 2004), ya que le da la posibilidad de conocer de nuevo el mundo. El vínculo y la seguridad cimientan las bases para vivir el desarrollo, vivir cada momento que va transitando.

El placer: es aquello que le permite a la maestra hacer lectura de lo que acontece con el niño, pues, a falta de lenguaje el cuerpo toma el lugar de texto comunicativo que posibilita la transformación mutua, reconocido este último aspecto como el sentido profundo de la comunicación. El placer o displacer se convierte en el significado que la maestra comprende desde el cuerpo de los niños, ese disfrute o goce son sinónimos de bienestar, condición indispensable para sentirse bien en un lugar y, en este caso, para realizar una acción. En sus palabras:

El disfrutar el placer de moverse, de sentir su cuerpo en movimiento, porque eso les genera a ellos ese placer de gatear, de llegar hasta cierto punto, de jugar, porque ellos juegan con todos los elementos que están ahi. (M.1, p. 52)

Hay placer en "sentir su cuerpo moverse", el placer de moverse es el placer de vivir un descubrirse a sí mismo y descubrir lo otro. El niño disfruta la experiencia dado que "llegar hasta cierto punto" es desentrañar sus propias potencias. La maestra entonces no solo caracteriza el movimiento con el placer, además lo identifica como señal de desarrollo.

La libertad: implica contar con un espacio de acción sin restricciones, pues ello hace posible la exploración corporal y el aprendizaje. Una de las maestras compara, desde su experiencia, el colegio y el jardín, 
atribuyendo a ambos espacios las posibilidades de aprendizaje, pero diferenciando las oportunidades de movimiento que ofrecen. La maestra afirma en las siguientes líneas que la experiencia de movimiento en el Jardín es más abierta que en el colegio, pues en este último los elementos propios de sus prácticas les ofrecen poca acción motriz, aspecto que no cree que incida en el aprendizaje porque "en ambos se aprende".

En el jardin si se aprende porque hay libertad, en el colegio los puestos y las sillas ya regulan y el niño dice "no, tengo que quedarme quieto." En el jardín eran actividades más cotidianas, porque por ejemplo el juego heuristico, en el colegio no, en el colegio es más conocimiento, los números, las letras, las vocales, cómo se relacionan las letras; entonces el niño ya se queda quieto, sentado el niño aprende, en los dos lugares se aprende, por ejemplo en el año en el que yo tuve a Paula y ella en el jardin era super pila, ahora aqui en el colegio también es super pila, en el colegio rinde muy bien, se ve que se aprende en los dos lados, hay casos en los que no, en los que les cuesta mucho más, es más difícil para ellos adaptarse a estar en una silla y en el jardín estaban libres corriendo con más movimiento. (M.2, p. 15)

Si se tiene en cuenta que la historia del cuerpo en la escuela se resume al esfuerzo por reducir sus potencialidades al aprendizaje de algunas técnicas corporales, no es raro entender cómo esta realidad objetiva hace parte del ser maestro; si bien cada aula existe de manera diferente, hay prácticas que anteceden al docente y a los estudiantes. Estas prácticas se naturalizan y se repiten con poca oposición, así se llega a pensar que los niños, aun cuando sean muy pequeños, aprenden quietos. Son aspectos socialmente aceptados transversales a la práctica escolar, así el movimiento no es indispensable para el aprendizaje pero matiza estos procesos con el componente de libertad en el espacio donde el cuerpo tiene protagonismo. Solo hace la diferencia el hecho de dejar ser al niño, se le permite actuar, incidir y decidir, asuntos realmente importantes a la hora de aprender, pues desde el movimiento Escuela Nueva (principios del siglo xx) se viene afirmando que la mejor manera en que el niño puede aprender desde la exploración es precisamente sintiendo libertad.

La imitación: no es la repetición de unos movimientos, ya que los niños no replican sin sentido las acciones que el adulto hace, su capacidad cognitiva y comunicativa les permite contextualizar esos movimientos o gestos de la maestra y comprender el mensaje. La imitación a la que se hace referencia es el acto creativo y comunicativo emergente del cuerpo mismo, es una transformación:

El hecho de uno mismo de expresarse corporalmente pues se genera que el niño también intente imitarlo. (M.1, p. 22)

ellos puedan ver que su cuerpo se puede mover en diferentes momentos, que más adelante vean la diferencia que hay con la experiencia, este momento ellos están más concentrados y ven lo que uno hace y lo imitan, y ven a sus compañeros que se mueven y se motivan a hacerlo, ellos hacian lo mismo y se descubre ahi. (M.2, p. 31)

El cuerpo claramente se transforma a partir de una relación con el otro, y estas transformaciones llenan el aula de un ambiente comunicativo tan vital y polifónico que habla de hitos de descubrimientos propios. Cada niño, dice la maestra, "se descubre ahi", se entera de las posibilidades comunicativas, corporales y relacionales que explora a través del placer del movimiento. Esta imitación funciona como una resonancia, como una respuesta, no como un efecto. El niño se anima, por una especie de apoyo colectivo, a explorar sus posibilidades psicomotrices, lo cual convierte la imitación en posibilitadora de descubrimientos.

La imitación, además, depende de una construcción de vínculos entre niños y adultos porque, como dice Wallon (1984), "el niño no imita más que a las personas por las que experimenta una atracción profunda, o las acciones que le han proporcionado placer" (p. 131). Por ello, las maestras saben que luego de construir un vínculo, los niños se comunicarán con ellas durante las actividades que propongan y podrán seguirlas; termina siendo una resonancia motriz llena de actitud empática.

\section{Creencias sobre desarrollo}

\section{El cuerpo posibilita las comprensiones de desa-} rrollo: al escuchar la preocupación de las maestras por observar el cuerpo, y desde alli diseñar sus propuestas, se devela la interlocución constante entre la pedagogía y las ciencias, leámoslo en estas palabras: 
básicamente porque es el que me da la base, me da la señal, porque yo tal y como veo al niño yo evalúo en términos del desarrollo, porque el niño tiene tal edad y no ha logrado ponerse en sus dos pies. (M.1, p. 80)

Desde esta observación, la maestra dispone a su juicio, basado en sus conocimientos sobre desarrollo, aquello que le comunican los cuerpos de los niños $y_{1}$ desde alli, moviliza sus esfuerzos para planear las estrategias que responderán a las necesidades de su grupo. El saber de la maestra empieza en la relación que establece con el cuerpo del niño, en lo que llega a conocer de él partiendo de las preguntas que se hace sobre su desarrollo y las maneras en que puede potenciarlo.

pues yo pienso es en el cuerpo porque uno crece y va mostrando que crece, que no es el mismo, entonces si yo hablo de desarrollo pues pienso en cuerpo, voy mirando en qué va, qué está haciendo, para ver en qué nivel está, el cuerpo le dice a uno en qué nivel está, si se para, si corre, si agarra, si no se mueve mucho. (M.2, p. 73)

El movimiento aparece como señal de desarrollo, ya que son las señales evidentemente físicas las que comunican a la maestra aspectos importantes en su proceso. Son los desplazamientos, la exploración de los entornos y la relación con los objetos los indicios de lo que está sucediendo en la vida de ese otro a quien acompaña esforzándose por entender el momento de desarrollo en el que se encuentra.

Consciente de que su voz corporal está siendo escuchada, comprende que los niños leen en su cuerpo asuntos tan triviales como que se va a cambiar la actividad, dándole así una oportunidad a cada quien de anticipar lo que sucederá y de prepararse para ello. Ese conocimiento compromete además el valor que sus mediadores comunicativos tienen, pues siempre hacen referencia al apoyo que ofrecen, como cuando dan la mano para provocar un lanzamiento de altura, cuando acercan objetos, o acunan para proveer calma. La voz del cuerpo de los niños mientras tanto, siempre irá comunicando a la maestra unos avances, como ellas los llaman, es decir, le provee una serie de elementos que interpretan, desde los cuales entienden el momento de desarrollo en el que se encuentran y se sirven de ellos para saber cómo disponerse para apoyar esos procesos.
El desarrollo se potencia a partir de la planeación y ejecución de experiencias: la elección de los materiales, espacios y tiempos en los cuales las maestras ejecutan sus propuestas conllevan un conocimiento amplio de quienes son sus niñas y niños, y lo que necesitan explorar para avanzar en sus procesos. Por ello, eligen dentro de la amplia gama de posibles acciones la que más se ajuste a las características motrices, estableciendo de entrada una relación entre las estrategias que utiliza y las características que evidencia desde la observación y relación con los niños.

Se debe trabajar la confianza, la edad es importante, entonces con el cesto pues ellos veían que la cuchara sirve para comer, el tarro sirve para meter cosas, la brocha para maquillarse, el cesto de los tesoros es muy importante porque ellos tienen contacto con esos objetos todos los días y los van conociendo, ellos se hacen preguntas, ellos dicen esto para qué me sirve y eso le sirve para su desarrollo y eso les sirve para la vida. (M.2, p. 79)

Los objetos ocupan un lugar importante porque sus utilidades dan pistas a los niños acerca del mundo que los rodea y las posibilidades de acción que tienen sobre él, construyen así conocimiento e interpelan la realidad al cuestionarse. Estos empiezan a verse como extensiones de las propuestas de las maestras, pues no son elegidos al azar, se revela la apuesta pedagógica de ellas, su conocimiento sobre el desarrollo de los niños y sobre lo que necesitan, su saber pedagógico se hace evidente en las elecciones del material para los niños.

Desde la voz de cada cuerpo las maestras identifican aquellos aspectos en los que los bebés necesitan apoyo y, con base en lo que el cuerpo les dice, planifican su acción pedagógica. Por ello, el planear depende en gran medida de la observación y la relación que han llevado a cabo acerca del cuerpo, la cual se registra en algunos instrumentos y lugares donde ellas reflexionan para entender los procesos de desarrollo. En este punto es importante decir que esta relación entre desarrollo, cuerpo y movimiento en la educación inicial es un asunto que enfrenta cada maestra con el fin de acoger las estrategias e instrumentos que en ocasiones le son asignados para comprender a los niños y dar cuenta de unos procesos. Valdría la 
pena establecer un diálogo mucho más cercano entre ese saber pedagógico de la maestra de inicial con esos modelos que intentan evaluar a cada niño, y posibilitar el diseño de instrumentos que dialoguen con los ritmos propios que las maestras identifican en el aula, ritmos tanto individuales como colectivos.

\section{Acerca de las creencias sobre desarrollo y su relación con el maestro}

Se comprende que el maestro cumple un rol importante en los procesos de los niños cuando:

\section{Acompaña corporalmente y observa}

El acompañamiento que las maestras hacen a los niños, en el marco de ese diseño de ambientes para el movimiento, está mediado corporalmente pues el contacto hace parte fundamental de acompañar. Ellas se acercan, tocan y sostienen, y en ese lenguaje comunican su presencia como espacio que alberga para contener el miedo a la exploración que todo niño tiene cuando el espacio no ha sido vivido. Esto permite comprender que, si bien los niños y niñas quieren explorar siempre su entorno, no se trata de un asunto innato que sucede por sí solo, por el contrario, es necesario un ambiente de acompañamiento y empatía corporal desde la comunicación psicomotriz para que la exploración tome la fuerza vital que contiene.

El contacto es importante, porque el ayudarlos, el sostenerlos, que vamos a montarnos en la pelota grande, que vamos a gatear, los agarramos, los tocamos y les generamos esa confianza a partir de nuestro contacto mutuo. (M.1, p. 40)

Esta acción de escucha y de actitud empática juega las veces de sostén emocional para los niños, porque les permite superar sus miedos y contiene sus emociones frente a un espacio u objetos a través del contacto.

La observación, por su parte, representa el momento a través del cual las maestras tienen la oportunidad de acercarse a los niños, a través de ella pueden conocerlos, saber qué tan dispuestos están para sus propuestas y sobre todo, desde alli, obtienen información acerca de su proceso de desarrollo:

la observación nos ayuda a decir este niño va aqui, el otro va aquí, es decir como a ver en qué etapa van, en qué tiempo van, porque uno no puede ver desde nada, o sea uno mira con respecto a unos tiempos, para cumplir y ya pues uno si ve algo que no está bien, pues trabaja en ello [...], pues como que uno ve que algo no está bien dentro de ese nivel o de ese desarrollo en el que debe estar el niño y lo ubica. (M.2, p. 93)

Es la observación y es la escucha atenta del cuerpo de los bebés la que les da indicios para acompañar, diseñar o repetir acciones, sin ella no podrian dar cuenta de los procesos, de las necesidades y las transformaciones que puede vivir cada uno de sus bebés. La observación parece ser un tema bastante álgido en sala materna, pues se construyen instrumentos como diarios de campo o libretas de apuntes donde las maestras consignan sus percepciones sobre lo que sucede con sus bebés. Estos instrumentos, por lo general, no son tan visibles, sin embargo valdría la pena acercarse a ellos y estudiarlos pues, según se entiende, la maestra se vale de lo que observa para potenciar el desarrollo, para planear sus acciones y relacionarse corporalmente con los niños. Por ello, estos instrumentos merecen, además, el tiempo para que la tarea de escribir acerca de sus observaciones se realice de la manera más tranquila posible, y salga de la obligatoriedad en la que en algunos lugares se encuentra.

De la lectura de esta polifonía depende entonces el desarrollo de cada uno de los bebés que tiene la maestra de maternal, las voces de los cuerpos se convierten en los lugares de enunciación para el desarrollo, porque dan significados particulares de lo que los bebés no solo necesitan, sino de lo que van construyendo a través del placer de crear, comunicar y pensar.

\section{Diseña ambientes}

La disposición de los objetos que hacen las maestras reviste al niño de cierto poder que le permite la acción misma, el poder que ejerce al actuar sobre el objeto, aquello que va experimentando por saberse protagonista, autónomo y llegar al placer de conocer el mundo.

siempre los objetos están distribuidos en toda el aula para que ellos mismos caminen o gateen... se acerquen por su propia fuerza, por su propia voluntad, empiecen a explorar, empiecen a moverse. (M.1, p. 52) 
Con estas palabras las maestras refieren aquello que el niño puede hacer, lo que ellas saben que les permitirá disfrutar del poder que provoca cada conquista motora, por esto la preparación de un ambiente rico en oportunidades posibilita la exploración de cada función motriz. Wallon (1984) es muy preciso al estudiar todo el esfuerzo motor y cognitivo que demanda la exploración de los objetos, dice que el cuerpo se va ajustando a esas necesidades que las manipulaciones de los objetos proponen, y aun ante la solicitud de movimientos precisos, no solamente las manos o los dedos están en función de responder a esa demanda, todo el cuerpo se implica y esto es lo que constituye las conquistas.

si, y pongo otros elementos alli arriba, empiezo a poner un sonajero, a poner que un espejito, porque ese objeto llamativo va a generar en el niño algo que lo va a motivar a desplazarse hasta allá. (M.1, p. 60)

Toda esta puesta en escena del material está mediada por una intención muy clara en las palabras de las maestras, ellas afirman que aquello que han seleccionado para el diseño del ambiente cumple una función, tiene un propósito de desarrollo. Las sillas, la rampa, los cojines, el sonajero, todo busca propiciar avances en el desarrollo motriz de los niños; caminar, desarrollar estabilidad, arrastrar son invitaciones que las maestras hacen a través de los objetos, por lo cual estas propuestas sobre el cuerpo tienen relación directa con el desarrollo de cada uno de ellos.

Así las cosas, el asunto de la planificación no es menor cuando de maestras de maternal se trata, pues leyendo el cuerpo de sus bebés potencian el desarrollo, a través de los criterios que construyen durante la cotidianidad del aula.

Ese poder que conlleva el moverse y actuar sobre otros soporta la construcción de conocimiento a través del placer de moverse y pensar, por ello se ponen objetos no para perfeccionar movimientos de cada parte del cuerpo, se dispone una serie de elementos para que el cuerpo se mueva libremente porque se reconoce su completitud, se entiende como unidad indisoluble.

\section{Repite las acciones que propone a los niños}

Wallon (1984) introduce el concepto de acto y efecto. Ligado al placer define aquello que sucede con el niño en sus primeros años, actuar sobre un objeto no es solo ser testigo del efecto que en este se produce, actuar produce placer al sentir el poder transformador implicado en él. El niño, entonces, se ve abocado a explorar nuevos movimientos poniendo la relación acto y efecto en un sentido circular. Según Wallon, no es una relación causal, es una relación que ofrece oportunidades para descubrir su cuerpo y sus posibilidades de acción sobre el mundo de los objetos o de los otros, que muy pronto se convertirán en el recurso del acto creativo. Para las maestras este asunto resulta importante y en su práctica van comprendiendo que es una necesidad que los niños y las niñas comunican:

pienso en lo que hacen los niños, en lo que no pueden hacer, ahi yo digo: "no, hay que repetir esto porque no lo hace aún", entonces nosotras las maestras de inicial repetimos mucho, no porque queramos, porque uno hay veces no quiere, pero como observamos, sabemos que necesitan más tiempo, que hay que hacerlo otra vez. (M.2, p. 87)

Las maestras comprenden desde el cuerpo del niño su necesidad de repetir acciones, darle el tiempo necesario para vivirlas una y otra vez hasta entenderlas y vivir el placer de actuar. Aucouturier (2004) agrega que "la oportunidad de repetir determina la duración de las acciones de trasformación, lo que permite una relación del niño con el tiempo, primer acercamiento a la conceptualización del tiempo histórico" (p. 130).

Esta repetición de las situaciones vividas en el aula les permite a los niños tan pequeños ir advirtiendo la presencia del otro, asunto de gran importancia si se quiere entender el camino que los niños recorren hasta la descentración, uno de los asuntos más cruciales y tal vez menos comprendidos. Por lo regular, se afirma que los niños pequeños son egocéntricos, incapaces de entender los puntos de vista de los otros, y claro el niño no puede leer la necesidad de otro, sin embargo estos primeros momentos donde el niño se percata de las acciones de los demás son el comienzo del conocimiento de esas otras voces.

Ese diseño de ambientes además es la oportunidad que cada bebé ha de tener para complejizar su exploración, pues ello reside en la posibilidad que tenga de volver sobre los elementos dispuestos para él. En este sentido, como las maestras lo afirman, repetir es de suma importancia para el desarrollo, ya 
que solo alli los niños construyen maneras diferentes de conocer la realidad que los rodea. La repetición entonces se privilegia y argumenta por parte de las maestras como condición de posibilidad para la construcción de conocimiento de cada niño o niña.

\section{A manera de conclusiones}

Acercarse a las creencias de las maestras significa adentrarse en su esencia profesional, es encontrarse con ese diálogo que establecen entre los conocimientos científicos que llegan a la escuela y comprender cómo transitan y cobran importancia en su acción pedagógica. Por ello, lo que hacen con los bebés puede entenderse a primera vista como una actividad de maternaje, sin embargo, el acercamiento a sus creencias permite comprender que involucra un proceso de pensamiento intelectual y una sensibilidad que la dispone para la comunicación corporal.

El desarrollo de los niños y las niñas se comprende desde la disposición corporal de las maestras para construir un tejido relacional en el aula, haciendo parte de ese tejido pueden acceder a los significados profundos que comparten con su grupo y que residen en la acción motriz. Desde esos significados sobre el movimiento, el cuerpo y el desarrollo ellas otorgan sentido profundo a la construcción de un vínculo, ofrecen situaciones para la imitación y leen el placer y displacer como unidades significativas que dan pistas sobre las necesidades y potencialidades de los niños y las niñas.

El vínculo supone unas acciones anteriores sobre las experiencias que provocan displacer, es decir, el vínculo reconoce la voz de displacer comunicada por los bebés y la maestra procura su seguridad afectiva así, por este camino, va fortaleciendo procesos importantes en el desarrollo. La libertad permite que el cuerpo pueda enfrentarse al placer y al displacer sin restricciones, el maestro allí puede comprender el lenguaje infantil que le da importantes señales sobre asuntos fundamentales de su desarrollo.

La imitación de las niñas y los niños lejos está de ser una acción sin significado o repetición sin sentido, en un espacio pedagógico la imitación tiene una carga afectiva que les abre la posibilidad de descubrirse a sí mismos y a eso otro que configura el entorno. La imitación cuando cuenta con libertad, en el sentido aqui tratado, se constituye en una potente oportunidad de desarrollo.

Las maestras acompañan el desarrollo de los niños y niñas al comprender que este es un proceso del cual ellas hacen parte activa, es un proceso que demanda su implicación corporal, su observación y sobre todo su reflexión para tener bases sólidas sobre las cuales planear y actuar en su tarea de ser maestras. Sin esto, las maestras terminarian haciendo actividades ajenas a la realidad de los niños y niñas, de los significados compartidos y de la cotidianidad del espacio compartido, construido, transformado $y_{\text {, en }}$ definitiva, vivenciado por los habitantes del aula.

Es una imperante necesidad abrir espacios de diálogo y cualificación acerca de la acción motriz y su relación con el desarrollo infantil, pues es claro que es desde el cuerpo que las maestras de maternal hacen sus lecturas de desarrollo, y estos espacios abririan la puerta a investigaciones sobre el campo de la infancia y el tejido polifónico que se construye desde el cuerpo.

Los cuerpos de maestras y bebés se transforman mutuamente para comunicarse, de manera que el flujo de intercambios significantes es constante, ese flujo va tejiendo unas redes afectivas que los unen y solo por esta vía puede la sala materna diseñar ambientes pedagógicos que posibilitan el desarrollo de los niños y niñas, respetando sus movilizaciones y sus esperas.

\section{Referencias}

Aucouturier, B. (2004). Los fantasmas de acción y la práctica psicomotriz. Graó.

Bonilla, E. y Rodríguez, P. (1997). Más allá del dilema de los métodos. Norma.

Carr, W. y Kemmis, S. (1988). Teoría critica de la enseñanza. Martínez Roca.

Lapierre, A. (1982). El adulto frente al niño de 0 a 3 años. Científico Médica.

Llorca, M., Ramos, V., Sánchez, J. y Vega, A. (2002). La práctica psicomotriz: una propuesta educativa mediante el cuerpo y el movimiento. Aljibe.

Marcelo, C. (1987). El pensamiento del profesor. CEAC.

Wallon, H. (1984). La evolución psicológica del niño. Crítica. 


\section{Diálogo del conocimiento}

Las preguntas que se hacen las maestras frente al trabajo que realizan con los niños y las niñas resultan fundamentales para movilizar comprensiones sobre su quehacer y potenciar trabajos que consoliden los sentidos de la educación inicial. Por ello, indagar por las creencias que orientan las acciones de las maestras permite, en primer lugar, reconocer su saber, construido a partir de las interacciones y observaciones cotidianas; $y$, en segundo lugar, hacer aportes importantes a quienes acceden a dichas construcciones. Una investigación que se pregunta por el cuerpo y el movimiento desde las comprensiones que tienen las maestras de educación inicial frente al desarrollo resulta pertinente en tanto se considera que este constituye la piedra angular de su quehacer, el asunto central de las intenciones y esfuerzos en el trabajo con niños y niñas de cero a tres años.

De los resultados se destaca el movimiento, el cual, a partir de las creencias de las maestras, revela, construye y vincula social, afectiva y cognitivamente al niño con el mundo que le rodea. Es innegable la interdependencia entre cuerpo, desarrollo y movimiento, no obstante, se da cuenta de una comprensión de este último como posibilidad y reto, pues permite explorar, conocer, conquistar a la vez que expresa, potencia y relaciona el mundo de las personas, los objetos, los espacios, las acciones en la vida de los niños y las niñas. El movimiento da cuenta del desarrollo y permite la configuración de un cuerpo propio, construido desde lo físico, lo social y lo cognitivo. Se destaca también, la importancia del trabajo pedagógico que implica proximidad, observación, acompañamiento y vínculo afectivo para dar lugar a experiencia y ambientes en los que los niños y niñas pueden explorar con libertad y placer.

Jenny Johana Castro Ballén 
